\title{
Heat Transfer and Thermal Stress Analysis of Circular Plate Due to Radiation Using FEM
}

\author{
Shubha Verma ${ }^{1}$ and V. S. Kulkarni ${ }^{2}$ \\ 1. Department of Mathematics, Ballarpur Institute of Technology, Ballarpur-442701, Maharashtra, \\ India. \\ 2. $\quad$ PG Department of Mathematics, University of Mumbai, Mumbai-400098, Maharashtra, India.
}

\begin{abstract}
The present paper deals with determination of transient heat transfer and thermal stresses analysis in a circular plate due to radiation. The radiation effect has been calculated by using Steffan's Boltmann law. The upper surface of circular plate is subjected to radiation, whereas lower surface is at constant temperature $T_{o}$ and circular surface is thermally insulated. The initial temperature of circular plate is kept at $T_{i}$. The governing 2-D heat conduction equation has been solved by using finite element method. The results for temperature distribution, displacement and thermal stresses have been computed numerically, illustrated graphically and interpreted technically.
\end{abstract}

Keywords: - Heat transfer analysis, Finite element method, Finite difference method, Thermal stresses analysis.

\section{INTRODUCTION}

In the early of nineteenth century the manufacturing industry was facing a critical problem of designing an advanced product with complex geometries, multi-material and different types of boundary conditions. Then the basic idea of finite element method was developed by Turner et al. [7] to obtain the solution of complicated problems. Since the actual problem is replaced it into a simpler form, one will be able to find its approximate solution rather than the exact solution. In the finite element method it will often be possible to improve or refine the approximate solution by spending more computational effort. Dechaumphai et al. [3] used finite element analysis procedure for predicting temperature and thermal stresses of heated products and analyzed heat transfer. Venkadeshwaran et al. [8] studied the deformation of a circular plate subjected to a circular irradiation path, coupled thermo-mechanical elasto-plastic simulation by finite element method. Laser forming of sheet metal is used for bending process, which is produced in the sheet by laser irradiation. Tariq Darabseh [2] studied the transient thermoelastic response of thick hollow cylinder made of functionally graded material under thermal loading using Galerkin finite element method. The thermal and mechanical properties of the functionally graded material are assumed to be varied in the radial direction according to a power law variation as a function of the volume fractions of the constituents and determined the transient temperature, radial displacement, and thermal stresses distribution through the radial direction of the cylinder. Sharma et al. [6] solved the two point boundary value problems with Neumann and mixed Robbin's boundary conditions using Galerkin finite element method which have great importance in chemical engineering, deflection of beams etc. The numerical solutions are compared with the analytical solution.

The present paper deals with the realistic problem of the thermal stresses of the isotropic circular plate due to radiation subjected to the upper surface, lower surface is at constant temperature $T_{o}$ and circular surface is thermally insulated with initial temperature at $T_{i}$. The governing heat conduction equation has been solved by using finite element method (FEM). The finite element formulation for thermoelastic stress analysis has been developed on the basis of classical theory of thermo elasticity and theory of mechanics of solid. Matlab programming is used to evaluate the transient temperature at different nodes and element thermal stresses in the circular plate. The results presented in this paper have better accuracy since numerical calculations have been performed for discretization of the large number of elements in the circular plate.

To our knowledge no one has developed finite element model for heat transfer and thermal stress analysis due to radiation in circular plate. This is a new and novel contribution to the field. The results presented here will be useful in engineering problems particularly in the determination of the state of stress in circular plate subjected to radiation. 


\section{MATHEMATICAL FORMULATION OF THE PROBLEM}

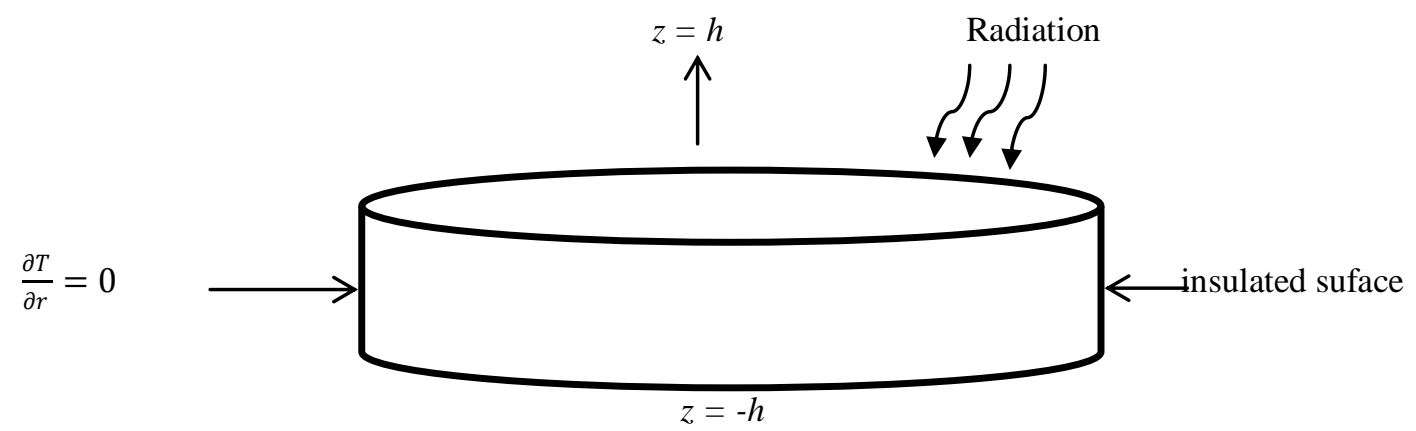

Figure 1: Geometry showing circular plate due to radiation

\section{Differential Equation}

Figure 1 shows the schematic sketch of a circular plate occupying space $D$ defined as $\{D: 0 \leq r \leq a,-h \leq z \leq$ $h$. Initially the circular plate is at arbitrary temperature $T i$. The upper surface of circular plate is subjected to radiation, whereas lower surface is at constant temperature $T_{o}$ and circular surface is thermally insulated. The governing axisymetric differential equation is given as

$$
k\left(\frac{\partial^{2} T}{\partial r^{2}}+\frac{1}{r} \frac{\partial T}{\partial r}+\frac{\partial^{2} T}{\partial z^{2}}\right)=c \rho \frac{\partial T}{\partial t}
$$

where $\rho$ is the density of the solid, $c$ is the specific heat, and $k$ is the thermal conductivity.

\section{Boundary condition}

The boundary conditions on the circular plate under radiation effect are as follows:

$\frac{\partial T}{\partial r}=0 \quad$ at $\quad r=a, t>0$

$k \frac{\partial T}{\partial z}=\sigma F\left(T^{4}-T_{\infty}^{4}\right) \quad$ at $\quad z=h, t>0$

$T(r, z, t)=T_{o} \quad$ at $\quad z=-h, t>0$

$T(r, z, t)=T_{i} \quad$ at $\quad t=0,0 \leq r \leq a,-h \leq z \leq h$

where $T_{\infty}$ is the temperature of the surrounding media, $T_{0}$ is the constant temperature, and $T_{i}$ is the initial temperature of the circular plate.

\section{GALERKIN FINITE ELEMENT FORMULATION}

On developing a finite element approach for two dimensional isotropic circular plate, following the David Hutton [4], one assumes two dimensional element having $M$ nodes such that the temperature distribution in the element is described by

$$
T(r, z, t)=\sum_{i=1}^{M} N_{i}(r, z) T_{i}(t)=[N]^{T}\{T\}
$$

where $N_{i}(r, z)$ is the interpolation or shape function associated with nodal temperature $T_{i}$, $[N]$ is the row matrix of interpolation functions, and $\{T\}$ is the column matrix (vector) of nodal temperatures.

Applying Galerkin's finite element method, the residual equations corresponding to equation (2.1) for all $i=1,2, \ldots \ldots \ldots$ are

$$
\iiint N_{i}(r, z)\left[k\left(\frac{\partial^{2} T}{\partial r^{2}}+\frac{1}{r} \frac{\partial T}{\partial r}+\frac{\partial^{2} T}{\partial z^{2}}\right)-c \rho \frac{\partial T}{\partial t}\right] r d r d z d \theta=0
$$

For the axisymmetric case the integrand is independent of the co-ordinate $\theta$, so the above equation becomes

$$
2 \pi \iint N_{i}(r, z)\left[k\left(\frac{\partial^{2} T}{\partial r^{2}}+\frac{1}{r} \frac{\partial T}{\partial r}+\frac{\partial^{2} T}{\partial z^{2}}\right)-c \rho \frac{\partial T}{\partial t}\right] r d r d z=0
$$

As $r$ is independent of $z$ so above equation becomes

$$
2 \pi \iint N_{i}(r, z)\left\{k\left[\frac{1}{r} \frac{\partial}{\partial r}\left(r \frac{\partial T}{\partial r}\right)+\frac{\partial}{\partial z}\left(r \frac{\partial T}{\partial z}\right)\right]-c \rho \frac{\partial T}{\partial t}\right\} r d r d z=0
$$

Integrating by parts the first two terms of the above equation

$$
\begin{gathered}
2 \pi \iint_{A}\left[k \frac{\partial N_{i}(r, z)}{\partial r} \frac{\partial T}{\partial r}+k \frac{\partial N_{i}(r, z)}{\partial z} \frac{\partial T}{\partial z}+\rho c N_{i}(r, z) \frac{\partial T}{\partial t}\right] r d r d z-2 \pi k \int_{0}^{a}\left[r N_{i}(r, z) \frac{\partial T}{\partial z}\right]_{z=-h}^{h} d r \\
-2 \pi k \int_{-h}^{h}\left[r N_{i}(r, z) \frac{\partial T}{\partial r}\right]_{r=0}^{a} d z=0
\end{gathered}
$$


Applying the boundary conditions of equation (2.2) and (2.3) the above equation reduces to

$$
\begin{aligned}
2 \pi \iint_{A}\left[k \frac{\partial N_{i}(r, z)}{\partial r}\right. & \left.\frac{\partial T}{\partial r}+k \frac{\partial N_{i}(r, z)}{\partial z} \frac{\partial T}{\partial z}+\rho c N_{i}(r, z) \frac{\partial T}{\partial t}\right] r d r d z \\
& =2 \pi \int_{0}^{a} N_{i}(r, h)\left(\sigma F\left(T^{4}-T_{\infty}^{4}\right)\right) r d r-2 \pi \int_{0}^{a} N_{i}(r,-h)\left[k \frac{\partial T}{\partial z}\right]_{z=-h} r d r
\end{aligned}
$$

Using the equation (3.1) the above equation becomes

$$
\begin{aligned}
2 \pi k \iint_{A}\left(\frac{\partial[N]}{\partial r} \frac{\partial[N]^{T}}{\partial r}+\frac{\partial[N]}{\partial z} \frac{\partial[N]^{T}}{\partial z}\right)\{T\} r d r d z+2 \pi \rho c \iint_{A}^{\cdot}[N][N]^{T}\{\dot{T}\} r d r d z & \\
& =2 \pi \int_{0}^{a} N_{i}(r, h)\left(\sigma F\left(T^{4}-T_{\infty}^{4}\right)\right) r d r-2 \pi \int_{0}^{a} N_{i}(r,-h)\left[k \frac{\partial[N]}{\partial z}\{T\}\right]_{z=-h} r d r
\end{aligned}
$$

For the radiation condition follow Singiresu Rao [5] and get

which is simplified as

$$
\begin{gathered}
2 \pi k \iint_{A}\left(\frac{\partial[N]}{\partial r} \frac{\partial[N]^{T}}{\partial r}+\frac{\partial[N]}{\partial z} \frac{\partial[N]^{T}}{\partial z}\right)\{T\} r d r d z+2 \pi \rho c \iint_{A}^{\cdot}[N][N]^{T}\{\dot{T}\} r d r d z \\
=2 \pi \int_{0}^{a} N_{i}(r, h)\left\{\sigma F\left(T^{2}+T_{\infty}^{2}\right)\left(T+T_{\infty}\right)\right\}\left(T-T_{\infty}\right)_{z=h} r d r \\
-2 \pi \int_{0}^{a} N_{i}(r,-h)\left[k \frac{\partial[N]}{\partial z}\{T\}\right]_{z=-h} r d r
\end{gathered}
$$

$$
\begin{gathered}
2 \pi k \iint_{A}\left(\frac{\partial[N]}{\partial r} \frac{\partial[N]^{T}}{\partial r}+\frac{\partial[N]}{\partial z} \frac{\partial[N]^{T}}{\partial z}\right)\{T\} r d r d z+2 \pi \rho c \iint_{A}[N][N]^{T}\{\dot{T}\} r d r d z \\
=2 \pi h_{r} \int_{0}^{a} N_{i}(r, h)\left[N_{i}(r, h)\right]^{T} r d r-2 \pi h_{r} T_{\infty} \int_{0}^{a} N_{i}(r, h) r d r \\
-2 \pi \int_{0}^{a} N_{i}(r,-h)\left[k \frac{\partial[N]}{\partial z}\{T\}\right]_{z=-h} r d r
\end{gathered}
$$

where $h_{r}=\sigma F\left(T^{2}+T_{\infty}^{2}\right)\left(T+T_{\infty}\right)$

This is of the form

where the characteristic matrix

$$
\left(\left[K_{c}\right]-\left[K_{r 1}\right]+\left[K_{r 2}\right]\right)\{T\}+[C]\{\dot{T}\}=-\left\{f_{r}\right\}
$$

$\left[K_{c}\right] \triangleq 2 \pi k \iint_{A}\left(\frac{\partial[N]}{\partial x} \frac{\partial[N]^{T}}{\partial x}+\frac{\partial[N]}{\partial x} \frac{\partial[N]^{T}}{\partial x}\right) r d r d z$
$\left[K_{r 1}\right]_{z=h} \triangleq 2 \pi h_{r} \int_{0}^{a} N_{i}(r, h)\left[N_{i}(r, h)\right]^{T} r d r$
$\left[K_{r 2}\right]_{z=-h} \triangleq 2 \pi k \int_{0}^{a} N_{i}(r,-h)\left[\frac{\partial[N]}{\partial z}\right]_{z=-h} r d r$

The capacitance matrix

$[C] \triangleq 2 \pi \rho c \iint_{A}^{\cdot}[N][N]^{T} r d r d z$

The gradient or load matrix

$\left\{f_{r}\right\} \triangleq 2 \pi h_{r} T_{\infty} \int_{0}^{a} N_{i}(r, h) r d r$

\section{ELEMENT FORMULATION}

Formulating the element shape functions as in Robert Cook et al. [1] and Singiresu Rao [5], the field variable is expressed in the polynomial form as $\emptyset(r, z)=a_{0}+a_{1} r+a_{2} z$ which satisfied the coordinate of the vertices of the triangle as $\left(r_{1}, z_{1}\right),\left(r_{2}, z_{2}\right),\left(r_{3}, z_{3}\right)$ and the nodal conditions $\emptyset\left(r_{1}, z_{1}\right)=\emptyset_{1}, \emptyset\left(r_{2}, z_{2}\right)=\emptyset_{2}, \emptyset\left(r_{3}, z_{3}\right)=$ $\emptyset_{3}$. Applying the nodal boundary conditions to obtain the interpolation function as

$$
\left[\begin{array}{l}
N_{1} \\
N_{2} \\
N_{3}
\end{array}\right]=\left[\begin{array}{lll}
1 & r & z
\end{array}\right]\left[\begin{array}{lll}
1 & r_{1} & z_{1} \\
1 & r_{2} & z_{2} \\
1 & r_{3} & z_{3}
\end{array}\right]^{-1}
$$

Solving above one obtains the shape function for the triangular element (three nodes) as

where the area of the triangular element is given by

$$
\begin{aligned}
& N_{1}(r, z)=\frac{1}{2 A}\left[\left(r_{2} z_{3}-r_{3} z_{2}\right)+\left(z_{2}-z_{3}\right) r+\left(r_{3}-r_{2}\right) z\right] \\
& N_{2}(r, z)=\frac{1}{2 A}\left[\left(r_{3} z_{1}-r_{1} z_{3}\right)+\left(z_{3}-z_{1}\right) r+\left(r_{1}-r_{3}\right) z\right] \\
& N_{3}(r, z)=\frac{1}{2 A}\left[\left(r_{1} z_{2}-r_{2} z_{1}\right)+\left(z_{1}-z_{2}\right) r+\left(r_{2}-r_{1}\right) z\right]
\end{aligned}
$$




$$
A=\frac{1}{2}\left[\begin{array}{lll}
1 & r_{1} & z_{1} \\
1 & r_{2} & z_{2} \\
1 & r_{3} & z_{3}
\end{array}\right] .
$$

The shape functions can also represented in terms of area $(A)$ co-ordinates system as

and the local co-ordinates $r$ and $z$ are represented as

$$
N_{1}=\frac{A_{1}}{A}, N_{2}=\frac{A_{2}}{A} \text { and } N_{3}=\frac{A_{3}}{A}
$$

$$
\begin{gathered}
r=N_{1} r_{1}+N_{2} r_{2}+N_{3} r_{3} \\
z=N_{1} z_{1}+N_{2} z_{2}+N_{3} z_{3} .
\end{gathered}
$$

\section{NUMERICAL CALCULATION}

The numerical calculations have been carried out for aluminum circular plate with the following parameters:

\section{Dimensions}

Radius $(r)=1 \mathrm{~m}$,

Height $(h)=0.05 \mathrm{~m}$.

\section{Material Properties}

Density of the solid $(\rho)=2700\left(\mathrm{~kg} / \mathrm{m}^{3}\right)$,

Thermal conductivity of the material $(k)=167\left(\mathrm{w} /\left(\mathrm{m}-\mathrm{K}^{0}\right)\right)$,

Specific heat $(c)=0.91\left(\mathrm{~kJ} / \mathrm{kg}-\mathrm{K}^{0}\right)$,

Linear coefficient of thermal expansion $(\alpha)=22.2 \times 10^{-6}\left(1 / \mathrm{K}^{0}\right)$,

Young's modulus of elasticity of the material plate $(E)=69(G P a)$,

Poisson's ratio $(v)=0.33$,

Stefan's Boltzmann's constant $(\sigma)=5.67 \times 10^{-8}\left(\mathrm{w} /\left(\mathrm{m}^{2}-\mathrm{K}^{0^{4}}\right)\right)$,

Emissivity of surface $(F)=0.03$.

Structural Properties

Number of nodes $(M)=18$,

Number of triangular elements $(N E)=20$.

Initial condition

Time $(t)=5 \mathrm{~min}$,

Temperature of surrounding media $\left(T_{\infty}\right)=313{ }^{0} \mathrm{~K}$,

Initial temperature $\left(T_{i}\right)=273{ }^{0} \mathrm{~K}$,

Temperature at lower surface $\left(T_{o}\right)=273^{\circ} \mathrm{K}$

\section{TEMPERATURE DISTRIBUTION}

a) Discretization of circular plate in finite element

For the discretization of circular plate into finite elements considering symmetry about $Z$ axis and right half of circular plate is shown in the figure 2. Circular plate is discretized into 18 numbers of nodes and 20 numbers of triangular elements.

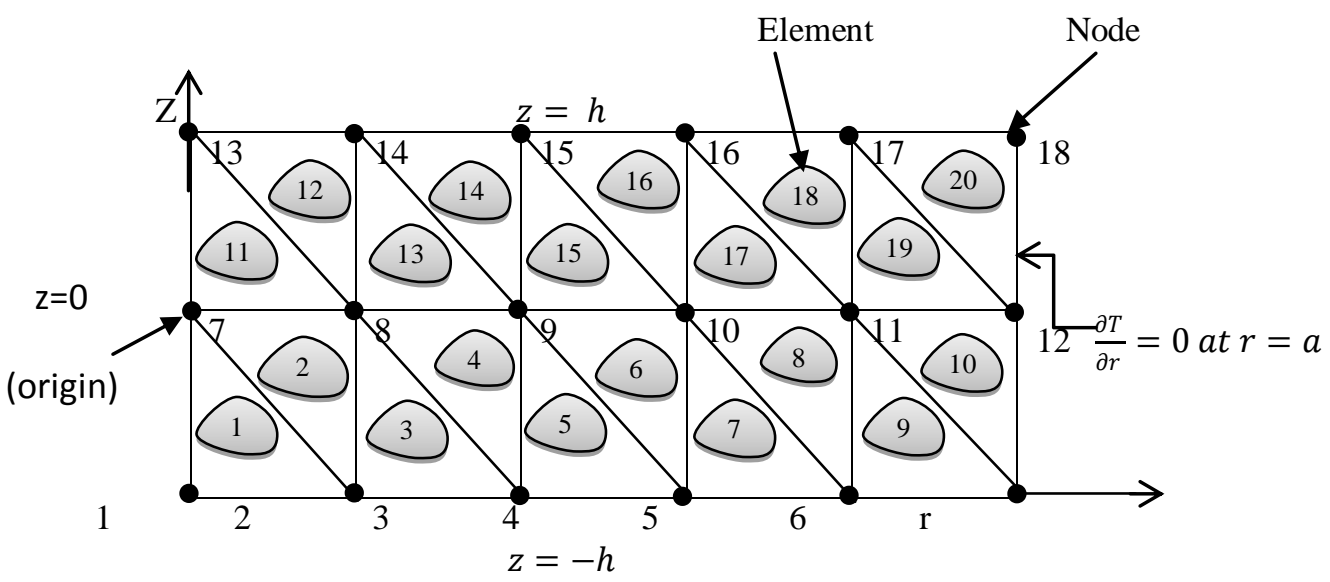

Figure 2: Geometry showing node and element position in the axisymetric circular plate 
b) Assembly procedure

Solving the equations (3.3), (3.4), (3.5), (3.6), (3.7), one obtains the elemental characteristic, elemental capacitance and elemental load matrix. Now assemble all 20 elements and formed the final equation which is expressed as

$$
\begin{gathered}
\left(\left[K_{c}\right]-\left[K_{r 1}\right]+\left[K_{r 2}\right]\right)\{T\}+[C]\{\dot{T}\}=-\left\{f_{r}\right\} \\
{[K]\{T\}+[C]\{\dot{T}\}=-\left\{f_{r}\right\}}
\end{gathered}
$$

Applying Finite Difference Method as in [4] and substituting

the above equation reduces to

$$
\{\dot{T}\}=\left\{\frac{T(t+\Delta t)-T(t)}{\Delta t}\right\}
$$

which is simplified as under

$$
[K]\{T\}+[C]\left\{\frac{T(t+\Delta t)-T(t)}{\Delta t}\right\}=-\left\{f_{r}\right\}
$$

$$
T(t+\Delta t)=\{T\}-[C]^{-1}\left\{f_{r}\right\} \Delta t-[C]^{-1}[K]\{T\} \Delta t
$$

Solving the above equation one obtains the temperatures on all the nodes at different time using Matlab programming. The numerical values of temperature distribution in the circular plate at time $t=5 \mathrm{~min}$ due to radiation is given in the table $l$ and graphical presentation of temperature variation along $r$ axis and $Z$ axis is shown in the figures $3(a)$ and $3(b)$, respectively.

Table 1: Calculated Temperature distribution at time $\boldsymbol{t}=\mathbf{5} \mathbf{m i n}$

\begin{tabular}{|c|c|c|c|c|c|c|}
\hline$z \backslash r$ & $r=0$ & $r=0.2$ & $r=0.4$ & $r=0.6$ & $r=0.8$ & $r=1$ \\
\hline$z=-0.05$ & 273 & 273 & 273 & 273 & 273 & 273 \\
\hline$z=0$ & 272.8379 & 273.081 & 273.1877 & 273.1008 & 272.7187 & 274.4366 \\
\hline$z=0.05$ & 273.1122 & 272.8317 & 272.7514 & 272.9992 & 273.095 & 270.4093 \\
\hline
\end{tabular}

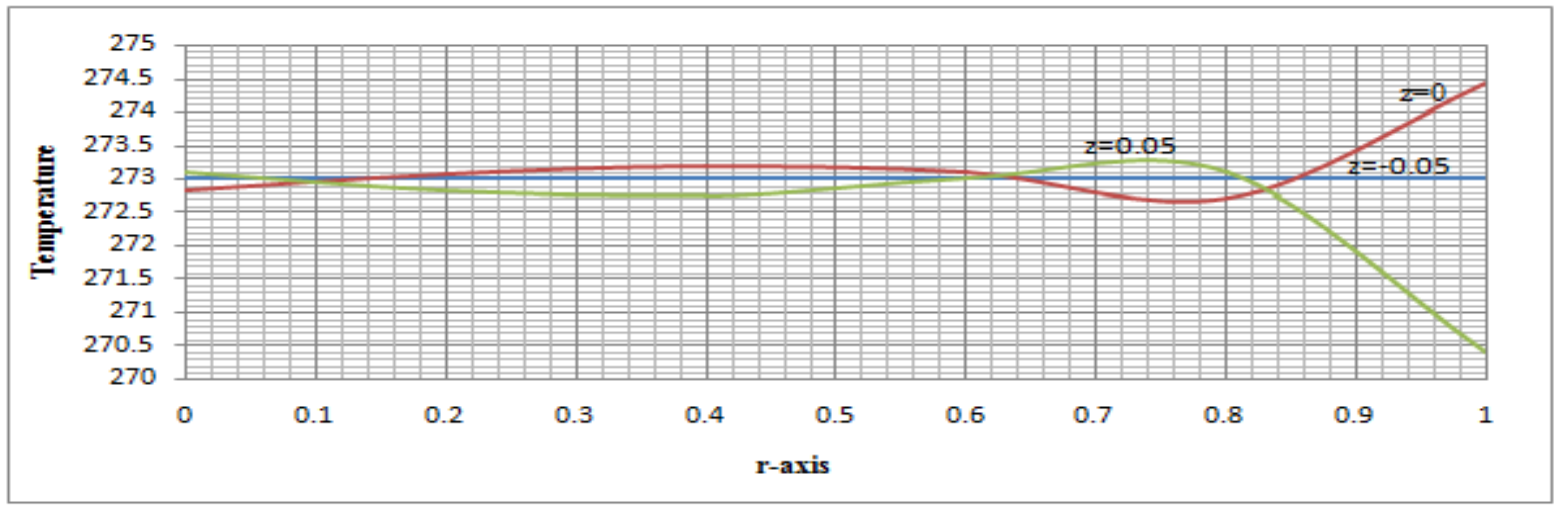

Figure 3(a): Temperature Distribution along radial direction at time $t=5 \mathrm{~min}$.

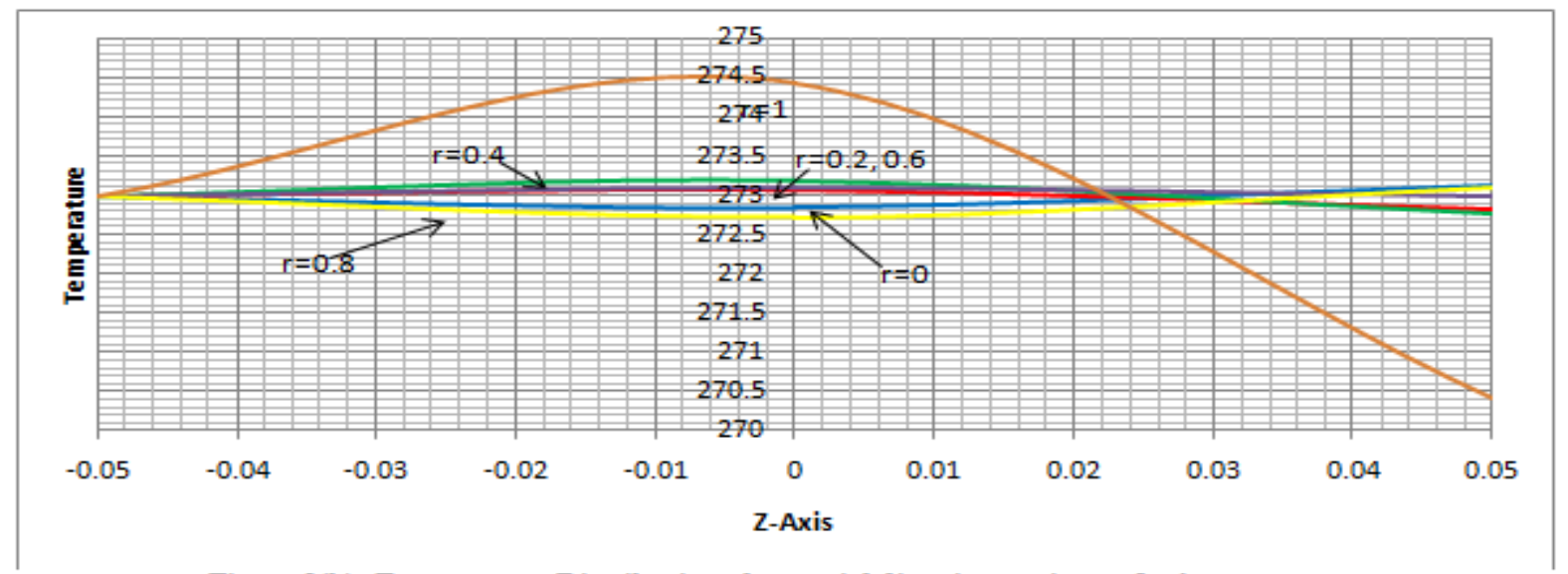

Figure 3(b): Temperature Distribution along axial direction at time $t=5 \mathrm{~min}$. 
VII.

DISPLACEMENT ANALYSIS

a) Discretization of displacement element

Following the approach of Robert cook et al. [1], the displacement components of node $j$ are taken as $q_{2 j-1}$ in the $\mathrm{r}$ direction and $q_{2 j}$ in the $Z$ direction. It denotes the global displacement vector as $Q=\left[q_{1}, q_{2}, q_{3}, \ldots \ldots \ldots \ldots q_{36}\right]^{T}$ as shown in the figure 4 .

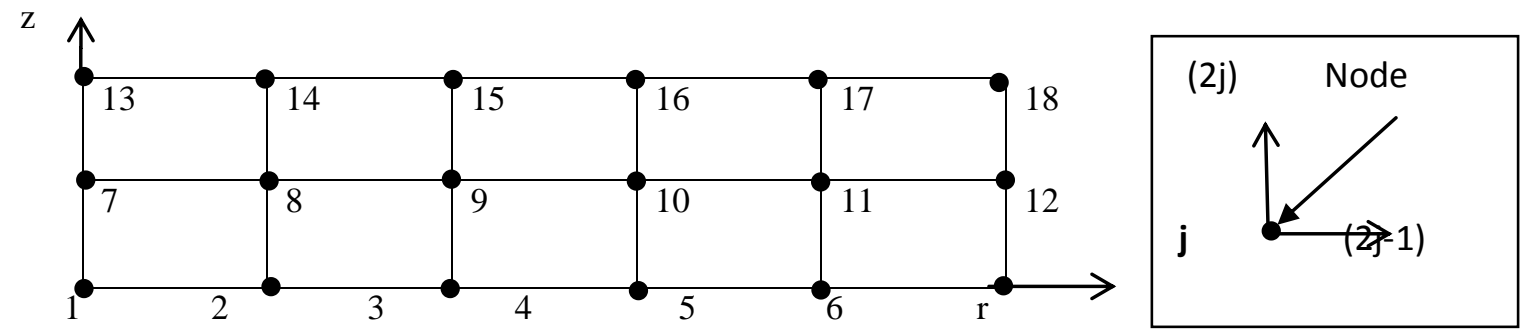

Figure 4: Geometry showing displacement component on the node in the circular plate

\section{b) Formation of elemental matrix}

The distribution of the change in temperature $\Delta T(r, Z)$ is known, the strain due to this change in temperature can be treated as an initial strain $\epsilon_{0}$.

The temperature difference $\Delta T$ is represented as

$$
\epsilon_{0}=[\alpha \Delta T, \alpha \Delta T, 0, \alpha \Delta T]^{T}
$$

$$
\Delta T=T_{i j}=T_{i}-T_{j} .
$$

The element stiffness matrix and element temperature load matrix is given below where

$$
\left[K^{e}\right]=2 \pi r A_{e} B^{T} D B \text { and }\left[\theta^{e}\right]=2 \pi r A_{e} B^{T} D \epsilon_{0}
$$

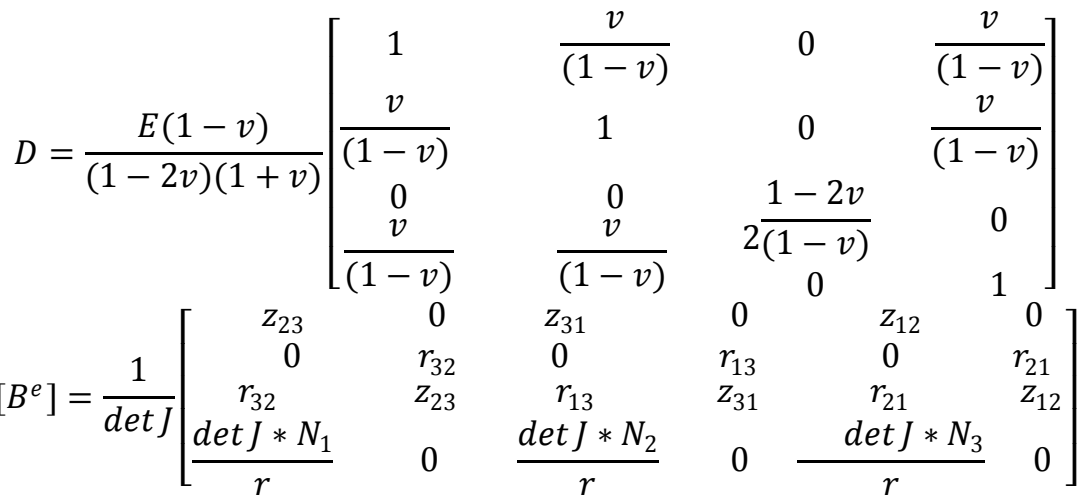

$$
\begin{aligned}
& J=\left[\begin{array}{ll}
r_{13} & z_{13} \\
r_{23} & z_{23}
\end{array}\right]
\end{aligned}
$$

Using the notation, $r_{i j} \triangleq r_{i}-r_{j}$ and $z_{i j} \triangleq z_{i}-z_{j}$.

\section{c) Assemble Procedure}

Assembling all the elemental stiffness and temperature load, the final stiffness matrix $\mathrm{K}$ and temperature load matrix $\theta$ are formed and expressed as

$$
K Q=\theta
$$

The above equation is solved by using Gaussian elimination method to yield the displacement $\mathrm{Q}$ at the nodes along radial and axial directions. The numerical values of displacement at time $t=5 \mathrm{~min}$. in a circular plate are given in the tables $2(a)$ and $2(b)$. The figures $5(a)$ and $5(b)$ shows graphical representation of displacements along radial $(r)$ and axial $(Z)$ directions respectively.

Table 2(a): Displacement along Radial direction at time $\boldsymbol{t}=5 \mathrm{~min}$.

\begin{tabular}{|c|c|c|c|c|c|c|}
\hline$z \backslash r$ & $r=0$ & $r=0.2$ & $r=0.4$ & $r=0.6$ & $r=0.8$ & $r=1$ \\
\hline$z=-0.05$ & $-3.8 E-07$ & $-5.2 E-07$ & $-3.9 E-07$ & $-4.4 E-07$ & $-8.59484 E-07$ & $-1.9 E-06$ \\
\hline$z=0$ & $5.42 E-08$ & $-4.2 E-07$ & $-8.6 E-07$ & $-8.2 E-07$ & $-1.77496 E-06$ & $-5.5 E-06$ \\
\hline$z=0.05$ & $-2 E-07$ & $1.82 E-08$ & $-1 E-06$ & $-1.3 E-06$ & $-1.65866 E-06$ & $-9 E-06$ \\
\hline
\end{tabular}




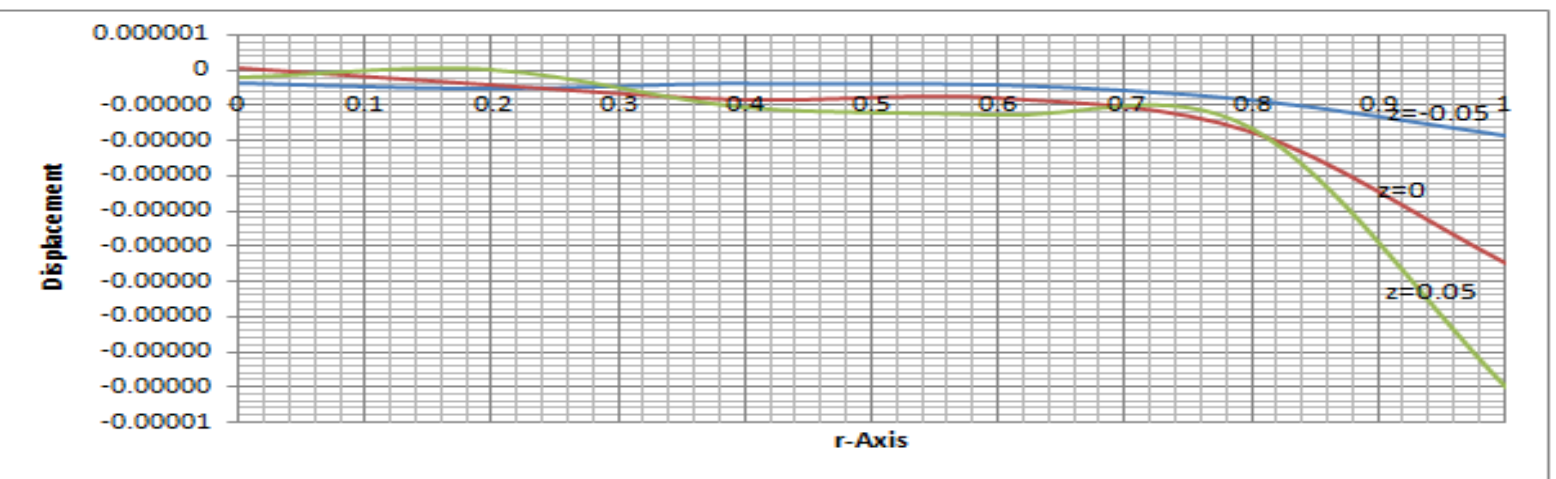

Figure 5(a): Displacement along radial direction at time $t=5 \min$.

Table 2(b): Displacement along axial direction at time $\boldsymbol{t}=\mathbf{5} \mathbf{m i n}$.

\begin{tabular}{|c|c|c|c|c|c|c|}
\hline$z \backslash r$ & $r=0$ & $r=0.2$ & $r=0.4$ & $r=0.6$ & $r=0.8$ & $r=1$ \\
\hline$z=-0.05$ & $-7.6 E-06$ & $-1.5 E-05$ & $-3.1 E-05$ & $-3.8 E-05$ & $1.52588 E-05$ & 0 \\
\hline$z=0$ & $-1.5 E-05$ & $-1.5 E-05$ & $-2.3 E-05$ & $-1.5 E-05$ & $-7.62939 E-06$ & $-1.5 E-05$ \\
\hline$z=0.05$ & $-7.6 E-06$ & $-2.3 E-05$ & 0 & 0 & $1.52588 E-05$ & $-1.5 E-05$ \\
\hline
\end{tabular}

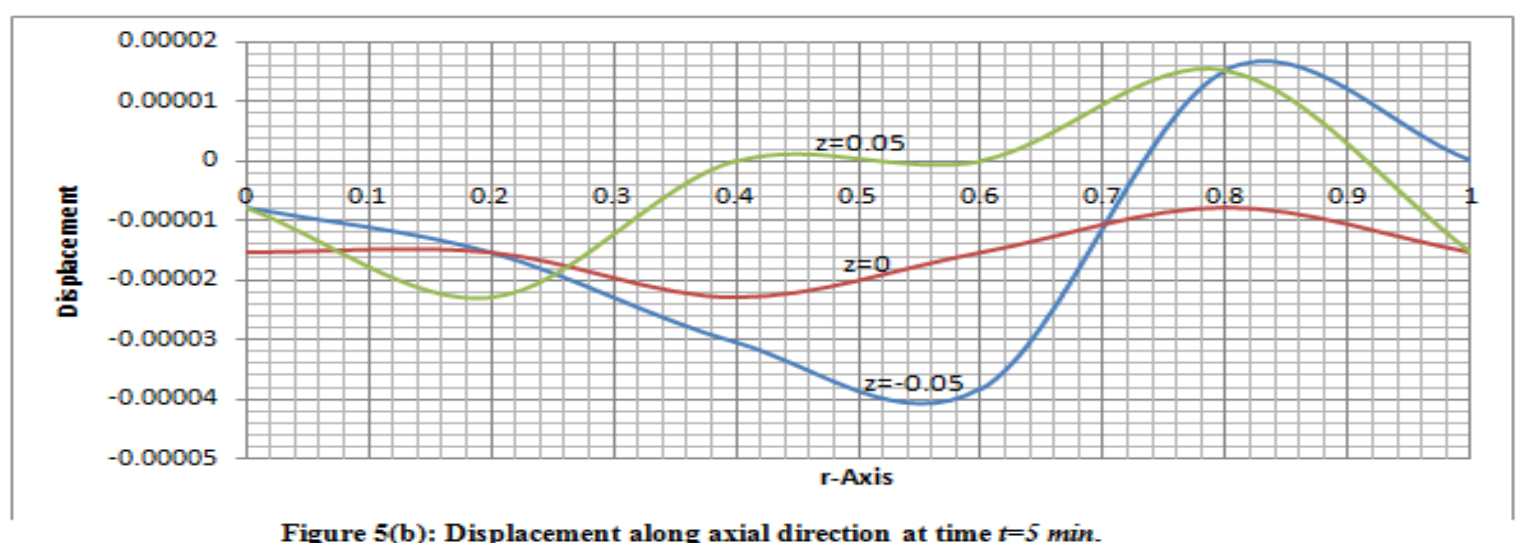

Figure 5(b): Displacement along axial direction at time $t=5 \mathrm{~min}$.

\section{STRESS ANALYSIS}

Determine the thermal stresses in radial, axial and resultant direction as in Robert cook et al. [1]. Using Straindisplacement relation, the elemental equation can be written in matrix form as

$$
\epsilon^{e}=B^{e} q^{e}
$$

Stress Strain relation is

$$
\sigma^{e}=E\left(\epsilon^{e}-\epsilon_{0}\right) \text { or } \sigma^{e}=E\left(B q-\epsilon_{0}\right)
$$

where $\epsilon_{0}=[\alpha \Delta t, \alpha \Delta t, 0, \alpha \Delta t]^{T}, \in=\left[\epsilon_{r}, \epsilon_{z}, \in_{r z}, \epsilon_{\theta}\right]^{T}$, and $\sigma=\left[\sigma_{r}, \sigma_{z}, \sigma_{r z}, \sigma_{\theta}\right]^{T}$.

Using the above results of displacements and temperatures at the nodes, obtain the thermal stresses in a circular plate at time $t=5 \mathrm{~min}$. along radial $(r)$, axial $(z)$, angular $(\theta)$ and resultant $(r z)$ directions are given in the tables $3(a), 3(b), 3(c)$ and $3(d)$ with graphical representation in the figures $6(a), 6(b), \sigma(c)$ and $\sigma(d)$, respectively.

\begin{tabular}{|c|c|c|c|c|c|c|c|c|c|c|}
\hline$Z \backslash r$ & \multicolumn{2}{|c|}{$0-0.2$} & \multicolumn{2}{|c|}{$0.2-0.4$} & \multicolumn{2}{|c|}{$0.4-0.6$} & \multicolumn{2}{|c|}{$0.6-0.8$} & \multicolumn{2}{|c|}{$0.8-1$} \\
\hline $\begin{array}{c}-0.05- \\
0\end{array}$ & $\begin{array}{c}-5.1 E- \\
05\end{array}$ & 0.00053 & $\begin{array}{l}4.52 E- \\
05\end{array}$ & $\begin{array}{c}- \\
0.0003 \\
2\end{array}$ & $\begin{array}{c}-1.5 E- \\
05\end{array}$ & $\begin{array}{c}0.00014 \\
8\end{array}$ & $\begin{array}{c}- \\
0.0001 \\
5\end{array}$ & $\begin{array}{c}0.000 \\
255\end{array}$ & $\begin{array}{c}- \\
0.0003 \\
6\end{array}$ & 0.0039 \\
\hline $\begin{array}{c}0- \\
0.05\end{array}$ & $\begin{array}{c}0.0002 \\
1\end{array}$ & $\begin{array}{c}0.00050 \\
4\end{array}$ & $\begin{array}{c}1.07 E- \\
05\end{array}$ & $\begin{array}{c}- \\
0.0002 \\
4\end{array}$ & $\begin{array}{c}- \\
0.0001 \\
2\end{array}$ & $\stackrel{-}{0.00046}$ & $\begin{array}{c}- \\
0.0009 \\
2\end{array}$ & $\begin{array}{c}- \\
0.000 \\
28\end{array}$ & $\begin{array}{c}0.0013 \\
59\end{array}$ & $\begin{array}{c}0.0015 \\
75\end{array}$ \\
\hline
\end{tabular}

Table 3(a): Radial stress $\left(\sigma_{r}\right)$ 
Heat Transfer And Thermal Stress Analysis Of Circular Plate Due To Radiation Using Fem

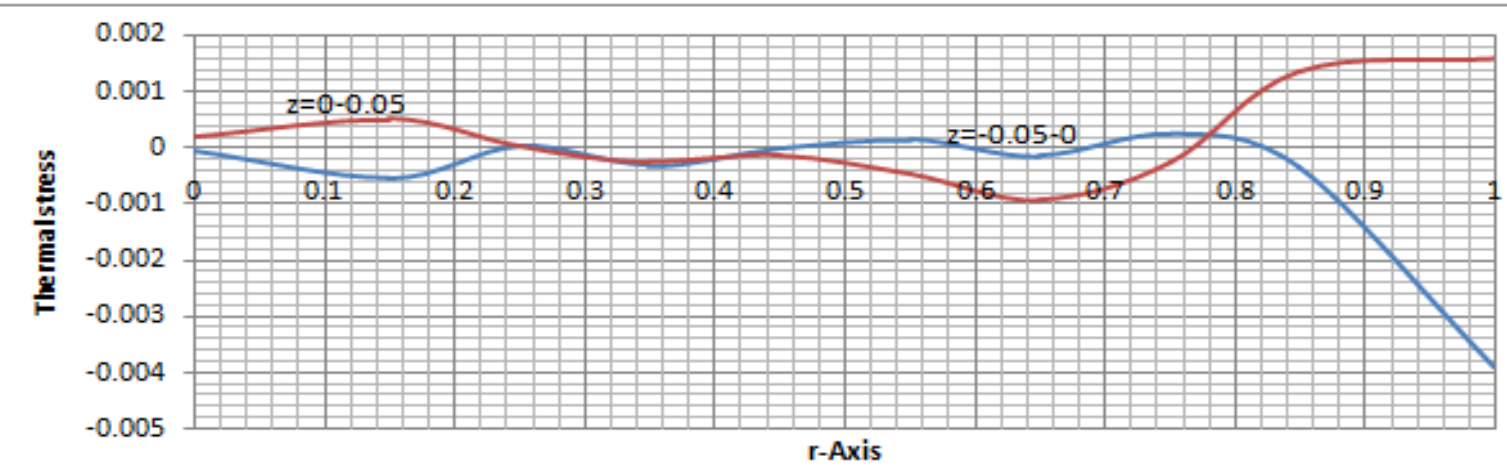

Figure 6(a): Radial stress $\left(\sigma_{r}\right)$ at time $t=5$ min.

Table 3(b): Axial Stress $\left(\sigma_{z}\right)$

\begin{tabular}{|c|c|c|c|c|c|c|c|c|c|c|}
\hline$Z \backslash r$ & \multicolumn{2}{|c|}{$0-0.2$} & \multicolumn{2}{c|}{$0.2-0.4$} & \multicolumn{2}{c|}{$0.4-0.6$} & \multicolumn{2}{c|}{$0.6-0.8$} & \multicolumn{2}{c|}{$0.8-1$} \\
\hline $\begin{array}{c}-0.05- \\
0\end{array}$ & -0.01078 & 0.000248 & 0.000124 & 0.010404 & 0.010816 & 0.031298 & 0.03174 & -0.03174 & -0.03202 & -0.02063 \\
\hline $\begin{array}{c}0- \\
0.05\end{array}$ & 0.010576 & -0.01058 & -0.01107 & 0.032131 & 0.03105 & 0.021592 & 0.021487 & 0.031156 & 0.029531 & 0.002055 \\
\hline
\end{tabular}

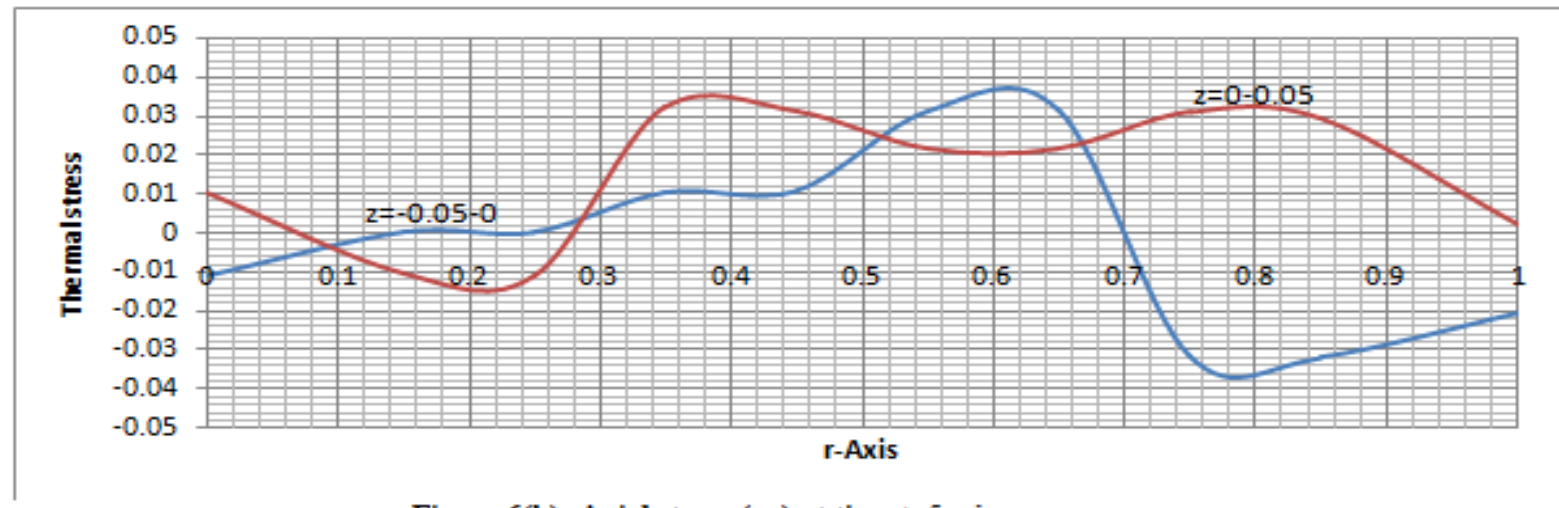

Figure 6(b): Axial stress $\left(\sigma_{z}\right)$ at time $t=5 \min$.

Table 3(c): Angular Stress $\left(\sigma_{\theta}\right)$

\begin{tabular}{|c|c|c|c|c|c|c|c|c|c|c|}
\hline$Z \mid r$ & \multicolumn{2}{|c|}{0.0 .2} & \multicolumn{2}{|c|}{$0.2-0.4$} & \multicolumn{2}{|c|}{$0.4-0.6$} & \multicolumn{2}{|c|}{$0.6-0.8$} & \multicolumn{2}{|c|}{$0.8-1$} \\
\hline$-0.05-0$ & -0.00049 & -0.00031 & 0.00017 & -0.00034 & $\begin{array}{c}4.14 E- \\
05\end{array}$ & 0.00018 & $\begin{array}{c}4.47 E- \\
05\end{array}$ & 0.000363 & 0.0006 & -0.00232 \\
\hline $0-0.05$ & 0.000482 & 0.000261 & $\begin{array}{c}-6.7 E- \\
05\end{array}$ & 0.000489 & 0.00093 & $\begin{array}{c}8.63 E- \\
05\end{array}$ & -0.0003 & -0.00073 & 0.0006 & 0.005707 \\
\hline
\end{tabular}

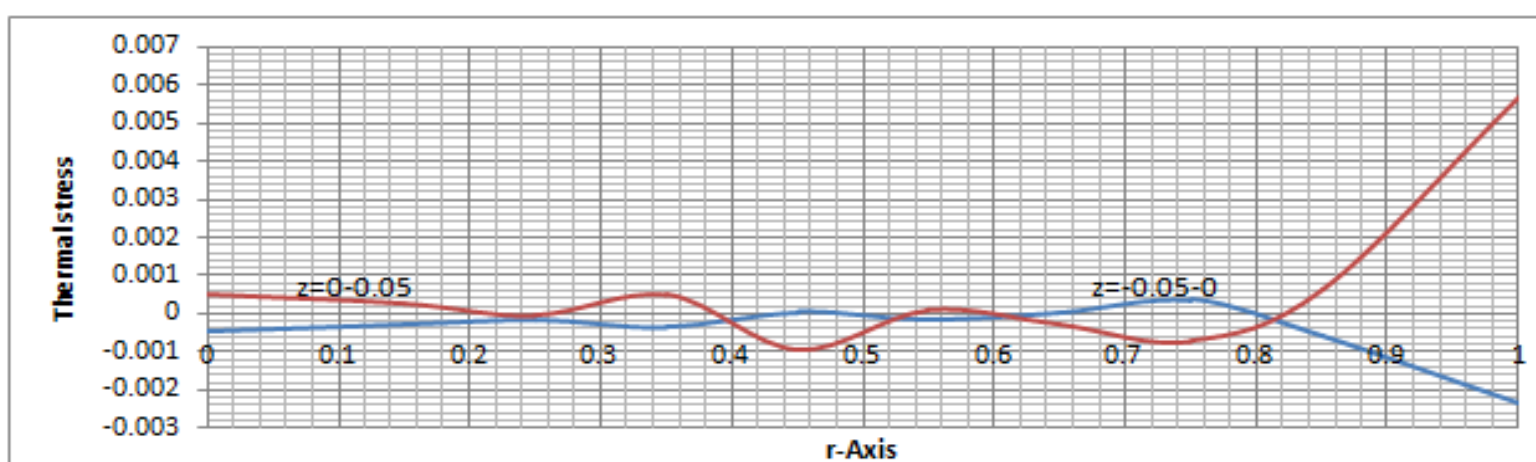

Figure 6(c): Angular stress $\left(\sigma_{\theta}\right)$ at time $t=5 \min$. 
Table 3(d): Stress along Resultant direction $\left(\sigma_{r z}\right)$

\begin{tabular}{|c|c|c|c|c|c|c|c|c|c|c|}
\hline$Z \mid r$ & \multicolumn{2}{|c|}{0.0 .2} & \multicolumn{2}{|c|}{$0.2-0.4$} & \multicolumn{2}{|c|}{$0.4-0.6$} & \multicolumn{2}{|c|}{$0.6-0.8$} & \multicolumn{2}{|c|}{$0.8-1$} \\
\hline$-0.05-0$ & 0.00204 & 0.000149 & 0.00512 & -0.00327 & -0.00327 & 0.002109 & 0.017902 & 0.001369 & 0.00653 & 0.00756 \\
\hline $0-0.05$ & 0.00035 & -0.00466 & 0.00203 & 0.007646 & 0.002382 & -0.00063 & 0.002003 & 0.005425 & 0.00247 & $0 . \overline{1543}$ \\
\hline
\end{tabular}

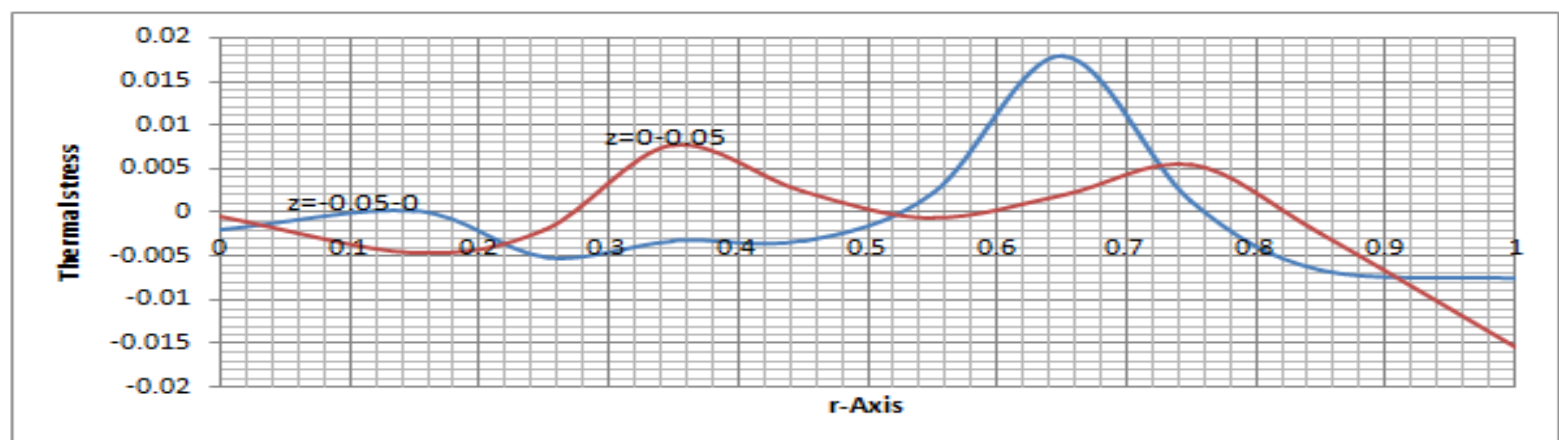

Figure 6(d): Stress along resultant direction $\left(\sigma_{r z}\right)$ at time $t=5$ min.

\section{CONCLUDING REMARKS}

In this manuscript the attempt has been made for the temperature distribution, displacement analysis and thermal stress analysis of the circular plate due to radiation using finite element analysis. For the better accuracy of the results the large numbers of elements are taken for discretization. The Matlab programming is used for the determination of numerical values for temperature, displacement and thermal stresses. The analyses predict temperature distribution, displacement due to temperature change and deformation formed by the thermal stress in circular plate. The numerical values and graphical representation of temperature distribution, displacement and thermal stress analysis are shown. The numerical result satisfies the equilibrium and compatibility conditions.

The temperature is changed with respect to time and the increase of temperature can be observed very high near the center region of insulated surface, high in middle region, and low at the top corner of the circular plate shown in the figures $3(a)$ and $3(b)$. From the figures $5(a)$ and $5(b)$ we observed the displacement is very high at center of curved insulated surface and high in the middle portion of the circular plate. The development of radial stress from figure $6(a)$ can be observed low near the insulated surface and slowly increase towards the center but the axial increase from bottom to top is shown in figure $6(b)$. The figure $6(c)$ shows an angular stress in the circular plate is varying in the central region and high near the insulated surface. The developments of resultant stresses from figure $6(d)$ seem high in the lower center and middle portion of the circular plate.

\section{REFERENCES}

[1] Cook Robert D., Malkus David S. and Plesha Michael E., "Concept and Application of Finite Element Analysis", John Wiley and Sons, New York, third edition, 2000.

[2] Darabseh Tariq T., "Transient Thermal Stresses of Functionally Graded Thick Hollow Cylinder under the Green-Lindsay Model”, World Academy of Science, Engineering and Technology, Vol. 59, pp. 23142318, 2011.

[3] Dechaumphai Pramote and Lim Wiroj, "Finite Element Thermal-Structural Analysis of Heated products", Chulalongkorn University Press, Bangkok, 1996.

[4] Hutton David, "Fundamentals of Finite Element Analysis", Tata McGraw-Hill Publishing Company Limited, New York, second edition, 2006.

[5] Rao S. Singiresu, "The Finite Element Method in Engineering", Elsevier publication, U. K., fourth edition, 2008.

[6] Sharma Dinkar and Jiwari Ram, Kumar Sheo, "Numerical Solution of Two Point Boundary Value Problems using Galerkin-Finite Element Method”, International Journal of Nonlinear Science, Vol. 13, No. 2, pp. 204-210, 2012.

[7] Turner M. J., Clough R. W., Martin H. C. and Topp L. J., "Stiffness and Deflection Analysis of complex structures", Journal of Aeronautical Sciences, Vol. 23, pp. 805-824, 1956.

[8] Venkadeshwaran K., Das S. and Misra D., "Finite Element simulation of 3-D laser forming by discrete section circle line heating", International Journal of Engineering, Science and Technology, Vol. 2, No. 4, pp. 163-175, 2010. 